\title{
PENINGKATAN KELARUTAN DAN LAJU DISOLUSI GLIMEPIRID MELALUI METODE KOKRISTALISASI
}

\author{
Fitrianti Darusman'), Sundani N Soewandhi' ${ }^{2)}$, Rachmat Mauludin ${ }^{3)}$ \\ ${ }^{1)}$ Prodi Farmasi, FMIPA, Universitas Islam Bandung, Indonesia \\ ${ }^{2}$ Sekolah Farmasi, Institut Teknologi Bandung, Indonesia \\ Email : efit_bien@yahoo.com
}

\begin{abstract}
ABSTRAK
Telah dilakukan kok al slimepirid (GMP) dengan asam oksalat (AO) menggunakan metode penggilingandan $p$ utan (n ggunakan pelarut aseton). Diagram fase sistem biner GMP-AOdigunakan untuk identifik? a pemben ikan interaksi antar kedua komponen serta ditegaskan kembali dengan analisis mik Kopik ngr an alat pemanas (hot stage) yang dihubungkan dengan mikroskop polarisasi. Padatan ha in worristalisasi dikarakterisasi dengan metode analisis termal (Differential Scanning Calorymetr , difralstmetri sinar-X serbuk (Powder X-Ray Diffraction), spektrofotometri inframerah (Fourier rans $n$-In, Red) dan mikroskopi (Scanning Electron Microscope). Hasil identifikasi dan karakteris $m$ unj kan interaksi eutektik antara kedua fase kristalin GMP-AO dalam keadaan padat pada perba ingan ar $3{ }^{-}$engan titik eutektik pada temperatur $128,7^{\circ} \mathrm{C}$. Selanjutnya, uji kelarutan dan laju diso meng an media dapar fosfat $\mathrm{pH} 7,4$. Kelarutan dan laju disolusi GMP hasil kokristalisasi meningkat oandin yan dengan campuran fisika dan senyawa tunggalnya.

Kata kunci : glimepirid, kokristalis, ri, e ktik, kelarutan dan laju disolusi.

\section{INCREASING SOLUBILY NI DISSOLUTION RATE OF GL MEV IDE}

THROUGH CO-CRMS LI AR ON METHOD

\section{ABSTRACT}

Co-crystallization of glimepiride (GMP) with oxalic ad lo) been carried out by grinding and solvent evaporation (acetone as a solvent) methods. Phase of binary system of GMPAO is used for initial identification of interaction between two npon $t$ as well as reaffirmed by microscopic analysis using a heater (hot stage) are associate wi a larization microscope. The solid phase was characterized by thermal analysis method (L feren, scanning Calorymetry), powder X-Ray diffractometry (Powder X-Ray Diffraction), infrared osce (10 ier TysformInfra Red) and microscopy (Scanning Electron Microscope). Solid state ir raction een GMP$\mathrm{AO}$ at a molar ratio $(3: 7)$ show a eutectic interaction at eutectical point $12{ }^{\circ} \mathrm{C}$. Ne evaluation on solubility and dissolution rate was carried out using phosphate buffer $\mathrm{pH}$ 7, as a dium. Solubility and dissolution rate of cocrystallization product of GMP increase compared to $\mathrm{p}$ scal mixture and its single compounds.
\end{abstract}

Keyword : glimepiride, co-crystallization, eutectic, solubility and dissolution rate. 


\section{Pendahuluan}

Glimepirid (GMP) adalah obat antidiabetik oral dari golongan sulfonilurea generasi ketiga yang mampu menurunkan kadar glukosa darah. GMP memiliki keunggulan penting dibandingkan dengan golongan sulfonilurea lainnya, yaitu dosisnya ndah, onset yang cepat, durasi kerja ng ama dan efek samping hipoglike yang $\mathrm{k}$ il. ${ }^{1}$ Namun GMP ini termas $\mathrm{ob}$ dalam $\mathrm{CS}$ kelas II dengan kelar an yan tidak larut dalam air, sehingga ber engaruh pada laju disolusi dan bioavai bilita Kelarutan GMP sangat dipen, arul o $\mathrm{h} \mathrm{pH}$ Pada media air, GMP menunjuk in ko ron angat kecil yaitu $<0,0$ 284 $\mathrm{mg} / \mathrm{m}^{\prime}$ da suhu $37^{\circ} \mathrm{C}$. Sedangkan pada me dapar ${ }^{\circ} \mathrm{H}>7$, kelarutan GMP sedikit eningl gaa $0,02 \mathrm{mg} / \mathrm{mL} .^{2,3}$

Berbagai teknik untuk meningkatxan kelarutan dan laju disolusi ob lah banyak dilaporkan seperti $p$ nbuat dispersi padat, pembentukan kompleks inklusi obat dengan pemı,awa siklodektrin, modifikasi senyawa menjad bentuk garam dan solvat, mikronisasi nanonisasi, polimorfisme, dan sebagainya. Salah satu teknik menarik dan sederhana yang baru-baru ini dikembangkan adalah kokristalisasi. Teknik ini dapat meningkatkan kelarutan dan laju disolusi obat-obat yang sukar larut dalam bentuk padat, dengan menggabungkan dua atau lebih komponen, dimana salah satunya bertindak sebagai host (tuan rumah) dan komponen lainnya bertindak sebagai guest (tamu) atau disebut juga cocrystal former (koformer), yang membentuk satu kristal secara bersama-sama melalui ikatan non kovalen. Teknik kokristalisasi ini dapat membentuk campuran eutektik sederhana, larutan padat (campuran kristal atau solid solution) dan senyawa molekular (fase kokristalin baru atau padatan kokristal).

Telah banyak dilaporkan penelitian tentang teknik kokristalisasi dalam upaya peningkatan kelarutan dan disolusi suatu zat aktif obat terutama yang termasuk dalam BCS kelas II, diantaranya karbamazepin dengan sakarin ${ }^{4}$ dan karbamazepin dengan nikotinamid ${ }^{5}$. Hasil kokristalisasi menunjukkan profil kelarutan yang lebih tinggi dibandingkan karbamazepin tunggal.

Pada GMP, penelitian dalam upaya peningkatan kelarutannya, antara lain dengan pembentukan senyawa kompleks inklusi GMP dengan dimetil $\beta$-siklodekstrin. ${ }^{6} \quad$ Pembuatan dispersi padat dengan menggunakan matriks polimer polivinilpirolidon dan gelucire menunjukkan peningkatan profil disolusi dari GMP. ${ }^{7,8}$ Namun, hingga saat ini teknik kokristalisasi dalam upaya peningkatan kelarutan dan disolusi GMP belum pernah dilaporkan.

Oleh karena itu, tujuan dari penelitian ini adalah untuk meningkatkan kelarutan dan laju disolusi dari GMP menggunakan teknik kokristalisasi dengan koformer yang sesuai.

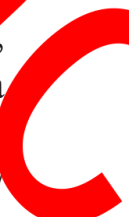

Tetode
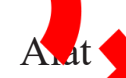

A,rofotometer UV-Vis (Beckman 7000 Spektrofotometer FT-IR, enge K Orb al (GFL 1092), difraktometer sina $A$ erb (Bruker D8 Advance), mik skop larisasi (Olympus BX-50), kame MO (o mp SC30), hot stage (Mk3 MRON cK5), instrumen DSC-TGA ( TA PT 0 , Linseis Thermal Analysis), Sc Electron Microscope (JSM-6510LV, JLL USA Inc.), dissolution tester (Beckman), timbangan analitik (Mettler Toledo AG204) dan vortex mixer (JEIO Tech).

Bahan

Glimepirid (Glenmark, India), asam oksalat (Sigma Aldrich), aseton p.a., metanol p.a., kalium dihidrogen fosfat p.a., dinatrium hidrogen fosfat p.a.

Prosedur

Karakteristik fisik GMP dan AO 
ditentukan dengan pengamatan pada mikroskop polarisasi, analisis termal dengan DSC, analisis kristalografi dengan PXRD, analisis gugus fungsi dengan FT-IR dan pengamatan morfologi dengan SEM.

Campuran biner GMP-AO disiapkan dengan melakukan pencampuran fisik pada berbagai komposis rdasarkan fraksi mol. Sifat fisik si- n bin dikarakterisasi dengan analic rmal D C kemudian dibuat diagn fase tem fer GMP-AO. Selanjutnya, dilakuk: lumtifikasi interaksi GMP-AO dengan nalisis mikroskopik menggunakan mik sko olan si yang dihubungkan dengan at am las (bat stage).

Interaksi yang tery me pakan campuran eutektik sederhana dan AO pada perbandingan mo 3:7 ang dibuat dengan teknik neat grindin (NG), solvent drop-grinding (SDG) dan solven evaporation(SE). Sampel hasilkokristalis dikarakterisasi dengan DSC, FT-IR, PXR dan SEM, kemudian dilakukan evaluasi kinerja kokristalisasi dengan pengujian kelarutan dan laju disolusi.

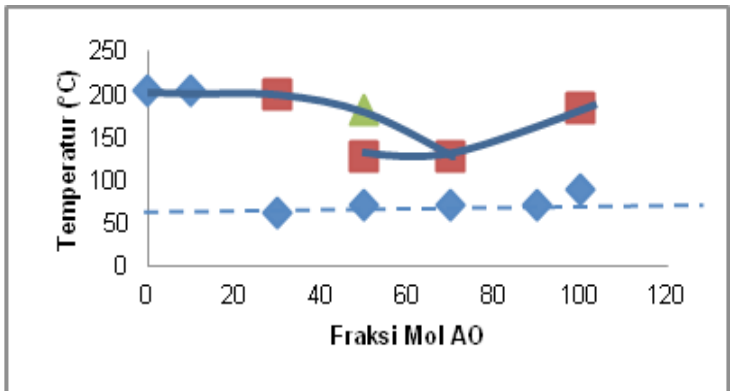

Gambar 1. Diagram fase sistem biner campuran fisika GMP dan AO ; TA = titik leleh GMP, TB $=$ titik leleh $\mathrm{AO}, \mathrm{TE}=$ titik eutektik

\section{Hasil dan Pembahasan}

Identifikasi interaksi GMP-AO dengan diagram fase (DSC) dan mikroskop polarisasi (HSM)

Diagram fase sistem biner GMPAO pada rasio molar (3:7) dari gambar 1 menunjukkan interaksi eutektik sederhana dengan titik eutektik $128,7^{\circ} \mathrm{C}$.

Untuk menegaskan interaksi yang terjadi antara GMP dan AO (3:7) adalah eutektik sederhana, dilakukan analisis mikroskopik polarisasi pada campuran fisika keduanya. Dari Gambar 2 hasil rekristalisasi menunjukkan tidak terbentuknya habit kristal baru, dimana GMP hanya terdispersi pada AO, sehingga menegaskan bahwa interaksi GMP-AO (3:7) merupakan eutektik sederhana.
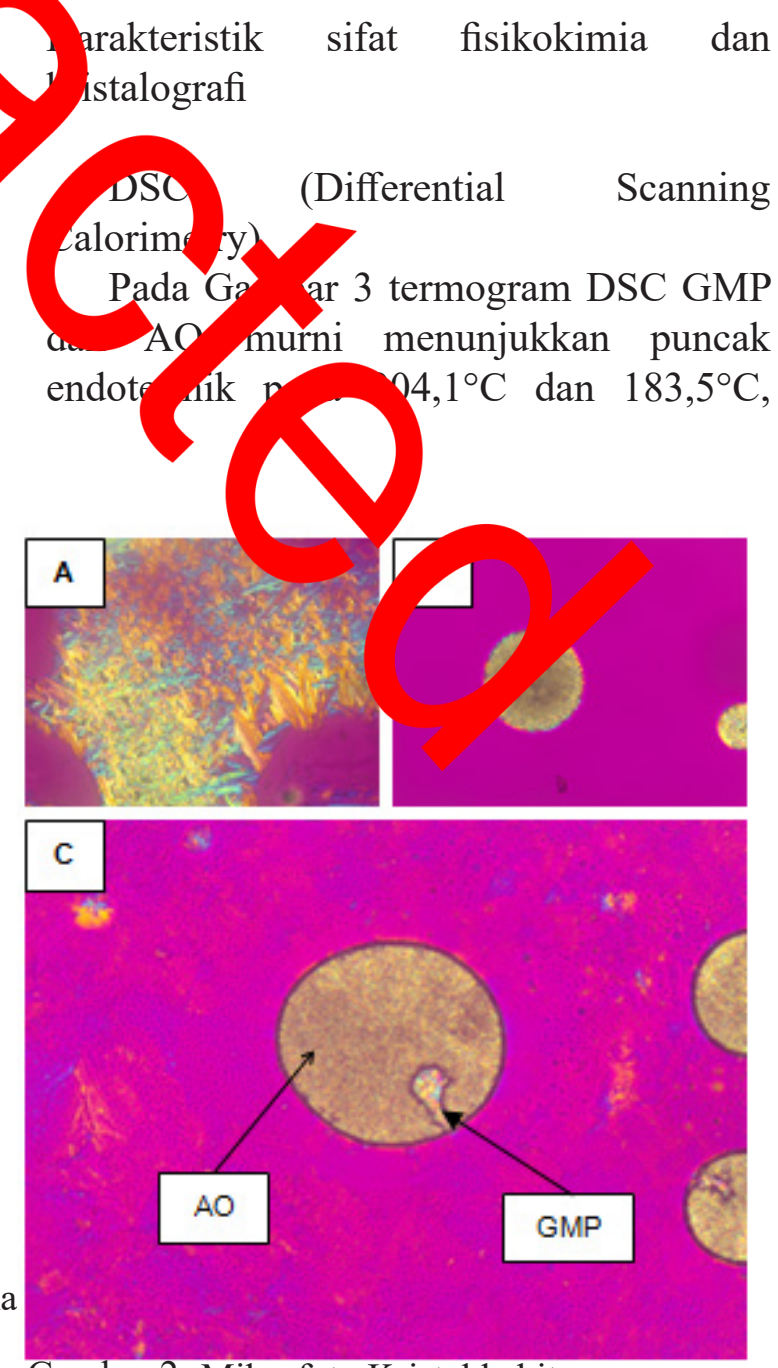

Gambar 2. Mikrofoto Kristal habit :

A) GMP, B) AO, C) GMP-AO 


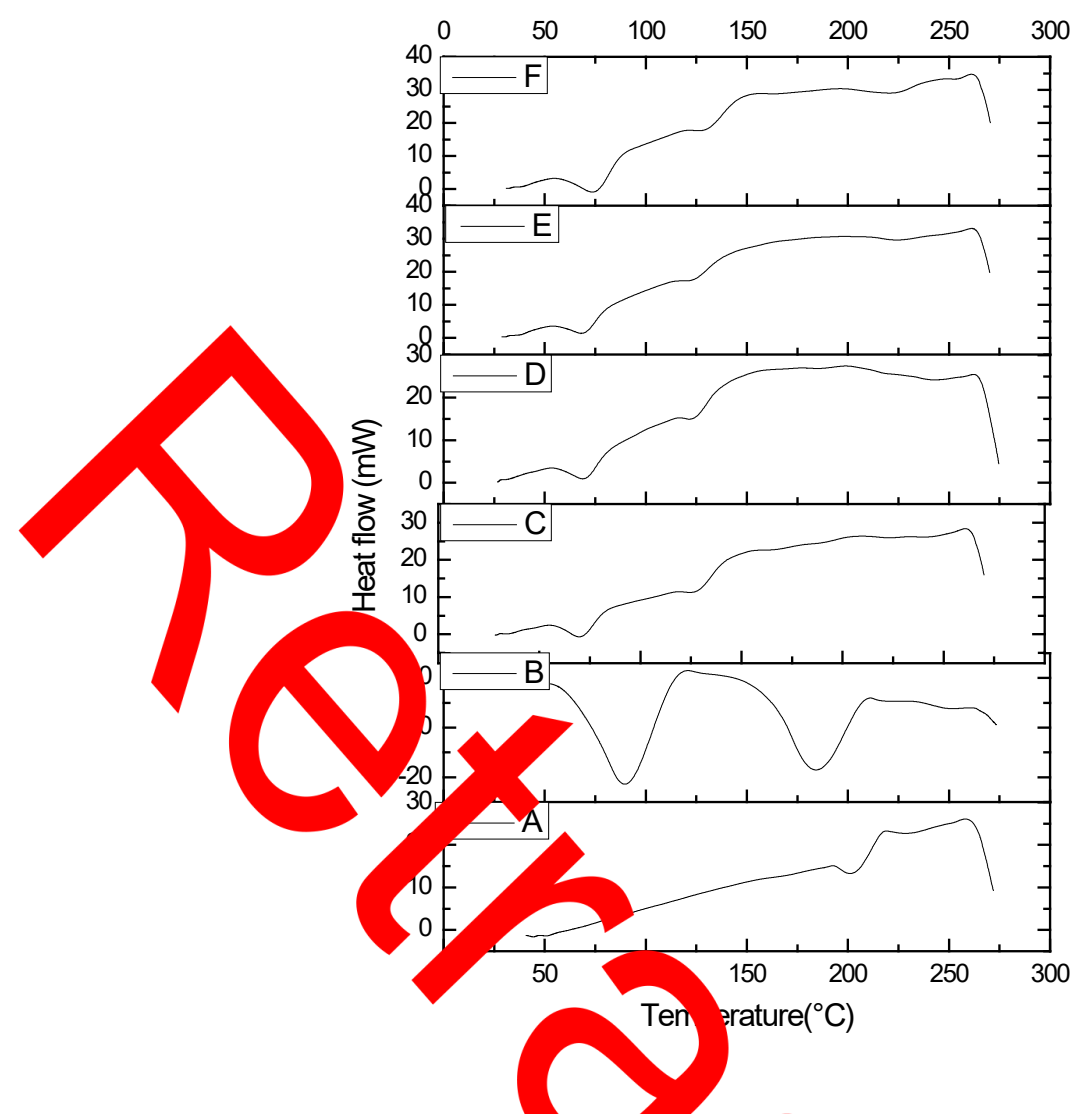

Gambar 3.Termogram DSC serbuk: A) GMP-AO (3:7) dari perlakuan N , E) Kristal asi GMP-AO (3:7) dari perlakuan SDG, F) kokristalisasi GMP-AO (3:7) dari per kuan SE

yang merupakan peristiwa leburan padatan masing-masing komponen (Gambar 3. A dan B). Dari termogram DSC ini mengindikasikan penurunan titik lebur sistem biner hasil kokristalisasi yang diduga terbentuknya campuran eutektik antara GMP dan AO pada $130,7^{\circ} \mathrm{C}$.

\section{PXRD (Powder X-Ray Diffraction)}

Dari gambar 4 difraktogram sinar-X terlihat bahwa padatan hasil interaksi antara GMP dan AO memiliki pola difraksi yang sama dengan campuran fisikanya, hanya berbeda pada intensitas puncak interferensi yang menunjukkan perbedaan derajat kristalinitas. Hal ini mengindikasikan bahwa kokristalisasi antara GMP-AO (3:7) dan tidak menghasilkan fase kristalin baru (senyawa molekular) melainkan konglomerasi kedua fasa kristal dalam keadaan padat atau disebut campuran

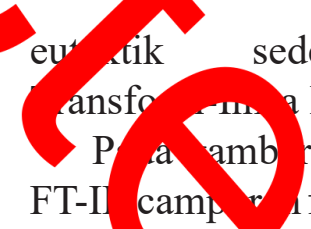

sederhana.FT-IR Red)

5 menunjukkan spektrum fisika sama dengan padatan hasil rectuan $\mathrm{AO}$ (3:7). Hal ini mempertegas awa ti ar erjadi interaksi kimiawi pac saat ses kokristalisasi kedua kompo

\section{SEM (Scanning Electron Microscope)}

Pada gambar 6 mikrofoto SEM, partikel GMP murni berukuran sangat kecil yaitu sekitar 0,5-5 $\mu \mathrm{m}$, dan terlihat adanya penggumpalan/aglomerasi. Hal inilah yang menyebabkan GMP bersifat hidrofobik sehingga praktis tidak larut dalam air.

GMP murni menunjukkan habit yang berbeda dengan AO (Gambar 6B). Namun padatan hasil perlakuan NG, SDG dan SE tidak menunjukkan habit yang berbeda bila dibandingkan antara GMP murni dengan 


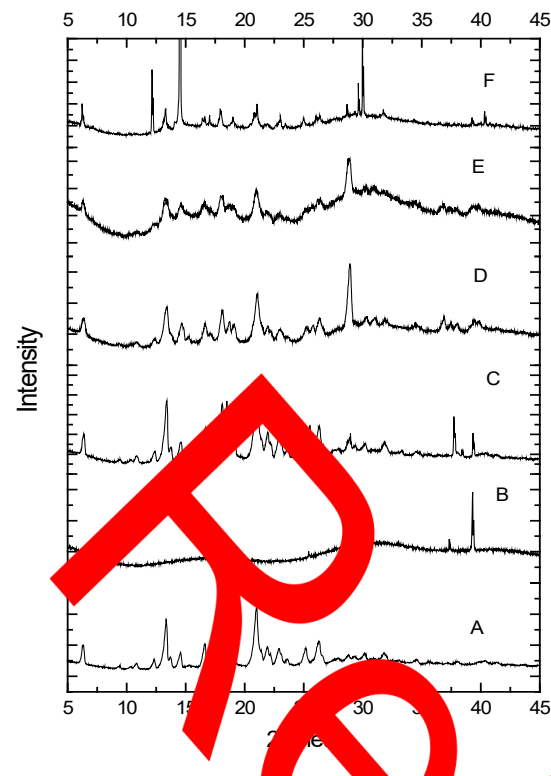

Gambar 4.Difraktogram inar- $\lambda$

GMP, B) AO, mpur tha GMP-AO (3:7), D)

GMP-AO (3:7) dari $\mathrm{p}$ akuan E) kokristalisasi GMP-A (? dari perlakuan SDG, F) kok,stalisasi GMP-AO (3:7) dari perlakuan SE

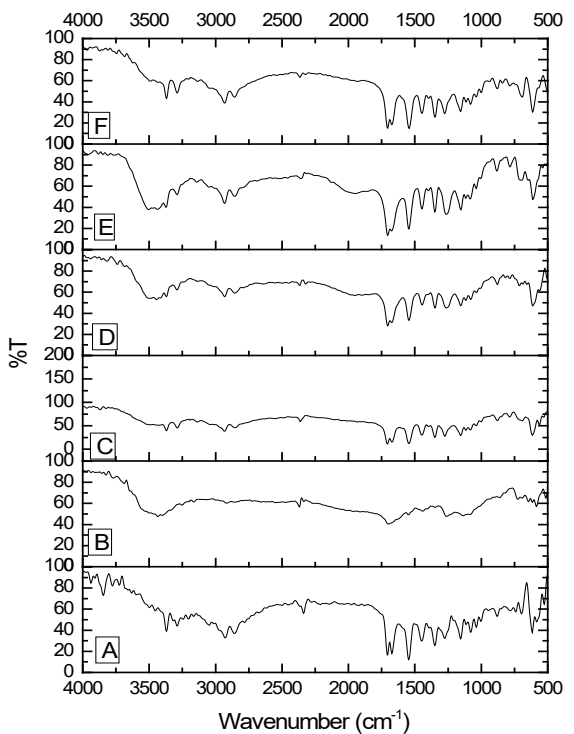

Gambar 5.Spektrum FT-IR dengan pelet $\mathrm{KBr}$ : A) GMP, B) AO, C) campuran fisika GMP-AO (3:7), D) kokristalisasi GMP-AO (3:7) dari perlakuan NG, E) kokristalisasi GMP-AO (3:7) dari perlakuan SDG, F) kokristalisasi GMP-AO (3:7) dari perlakuan SE. campuran fisika GMP-AO.

Padatan hasil perlakuan menunjukkan ukuran partikel yang paling besar, karena tidak adanya proses pengecilan ukuran partikel. Hal ini ditegaskan pula dari difraktogram perlakuan SE yaitu menunjukkan intensitas puncak paling tinggi, yang berarti derajat kristalinitas yang lebih tinggi pula. Sedangkan padatan

\section{(1)}

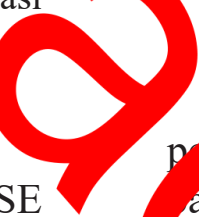

p SDG menunjukkan ukuran artikel ang paling kecil, relevan dengan difraktosran $s$ DG yang menunjukkan an-p âl yang landai/rendah, yang berarti rajat amarfus yang tinggi pula.
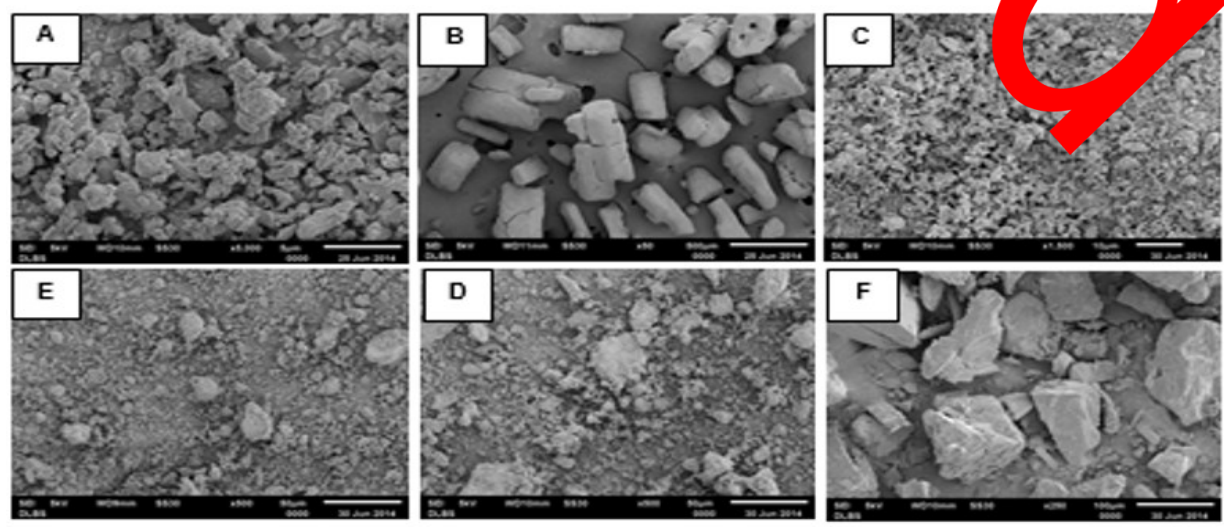

Gambar 6. Mikrofoto SEM serbuk : A) GMP (0-5-5 $\mu \mathrm{m})$, B) AO $(100-500 \mu \mathrm{m}$, C) campuran fisika GMP-AO (3:7) (1-10 $\mu \mathrm{m}), \mathrm{D})$ kokristalisasi GMP-AO (3:7) dari perlakuan NG (1-25 $\mu \mathrm{m})$, E) kokristalisasi GMP-AO (3:7) dari perlakuan SDG (1-25 $\mu \mathrm{m})$, F) kokristalisasi GMP-AO (3:7) dari perlakuan SE $(10-100 \mu \mathrm{m})$. 
Tabel 1. Hasil uji kelarutan GMP-AO (3:7)

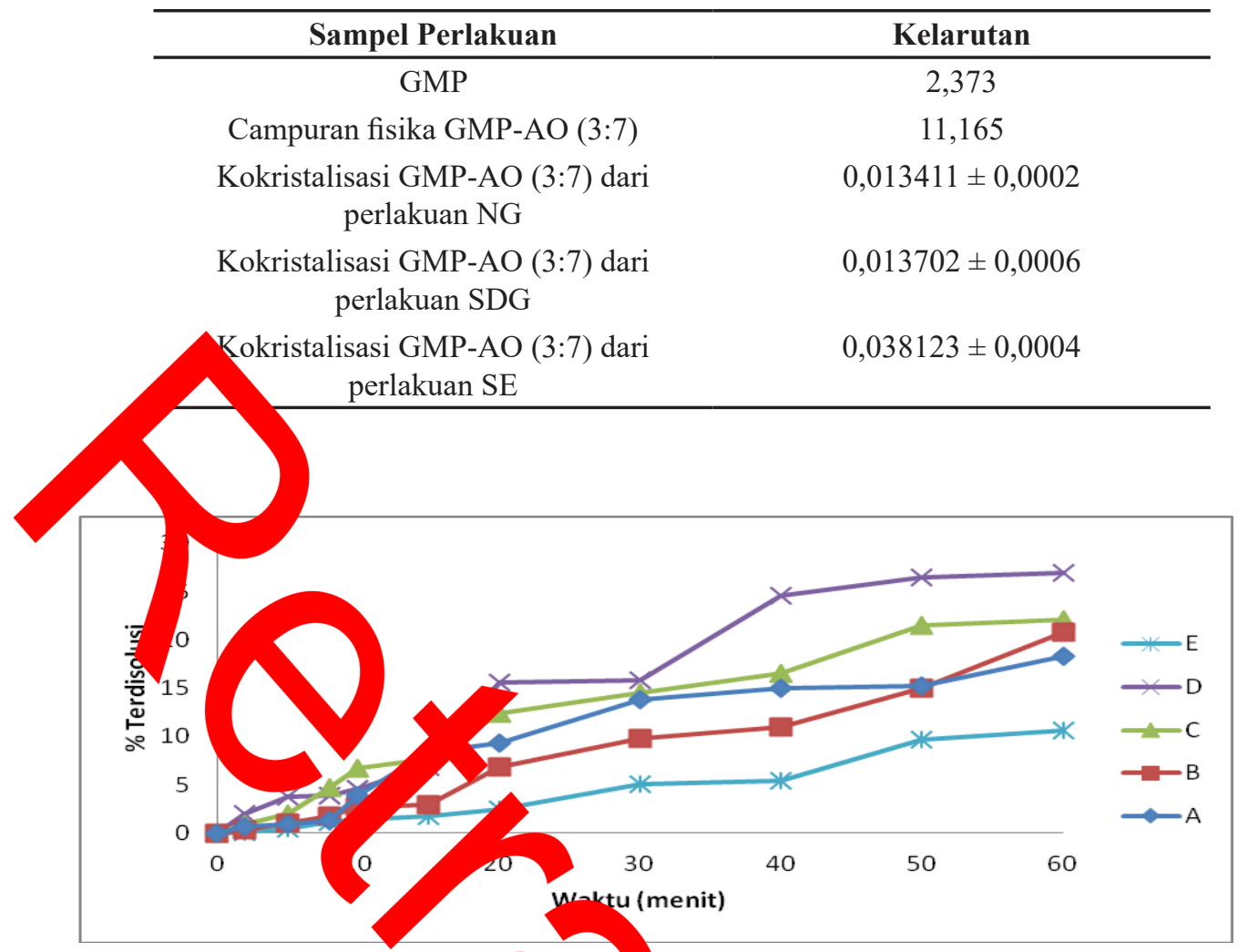

Gambar 7. Profil laju disolusi serbuk : A GMur , B. Campuran fisik GMP-AO (3:7), C. kokristalisasi GMP-AO (3:7) dari perlaku n NG, cokristalisasi GMP-AO (3:7) dari perlakuan SDG, E. kokristalisasi GMP-AO (3:7)

GMP-AO (3:7) dilakukan penetapan kadar GMP terlarut secara spektrofotometri ultraviolet pada panjang gelombang serapan maksimum $228 \mathrm{~nm}$.

Peningkatan kelarutan dan laju disolusi GMP dengan kokristalisasi menggunakan AO terjadinya karena interaksi eutektik dengan mekanisme pengurangan ukuran partikel akibat perlakuan penggilingan/ grinding (SDG) sehingga menjadi lebih amorf.

Namun pada GMP-AO perlakuan SE menunjukkan profil disolusi yang paling rendah daripada perlakuan SDG. Hal ini disebabkan ukuran partikel GMP-AO perlakuan SE yang besar dan tidak mengalami proses pengayakan terlebih dahulu. Ukuran partikel sangat mempengaruhi laju disolusi, dimana semakin kecil ukuran partikel atau semakin besar luas permukaan kontak, maka laju disolusi akan semakin cepat. Disamping itu 


\section{Daftar Pustaka}

1. Ammar, H.O., H.A. Salama, M. Ghorab, A. Mahmoud. Formulation and Biological Evaluation of GlimepirideCyclodextrin-Polymer Systems. Int. J. Pharm. 2006;309, 129-138.

2. Vishweshwar, P., Weyna, D.R., Shattock, T., dan Zaworotko, M. J. Synthesis and Structural $C^{\prime}$ cterization of $\mathrm{Co}$ crystal and P' maca tical Co-crystal. Mechanoc try vs S v Evaporation from ation. Crys Growth \& Design.2009. Vo ty, 0. 2 : 1106-1123.

3. Nichols, Dik. Salid State Characterizatic of narn ceuticals, R.A., Storey., I. Yme Jo Wi y\& Sons Ltd., United Kingd n. $20,28+6$.

4. Hickey, M. B., Jon, Scoppettuolo, L. A. Morris e, S. Vetter, A. Guzman, H., emen F., Zhong Zhang, Tawa, M. D Aaley, S., Zaworotko, M. J., and Almarsso Orn. Perfomance Comparison a Co-Crystal of Carbamazepine with Marketed Product, European Journal of Pharmaceutics and Biopharmaceutics. 2007;67, 112-119

5. Buanz, A. B. M., Parkinson, G. N., \& Gaisford, S. CarbamazepineNicotinamide Cocrystal of Polymorphs with Rapid Heating DSC and XRPD. Crystal Growth \& Design. 2011 : 1177-1181.

6. Ammar, H.O., H. A. Salama, M. Ghorabb, A. A. Mahmoud. Inclusion complexation of glimepiride in dimethyl- $\beta$-cyclodextrin. Asian Journal of Pharmaceutical Sciences. 2007.

7. Liu, R., 2000, Water Insoluble drug Formulation, Taylor and Francis Group, Boca Raton, London, New York. 493-517

8. Rana R.M, Randa L, Ehab A.H, Omaima N. Optimization for Glimepiride Dissolution Enhancement Utilizing Different Carriers and Techniques. Journal of Pharmaceutical Investigation, Springer. 2013.

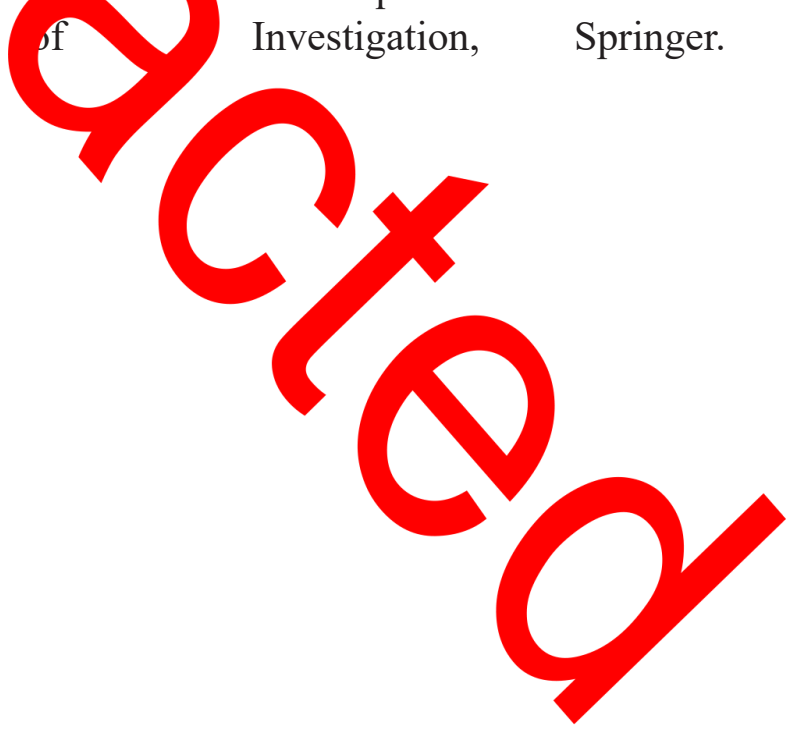

